Psychopharmacologia (Berl.) 31, $291-304$ (1973)

(C) by Springer-Verlag 1973

\title{
The Effects of Stimulants and Depressants on Cocaine Self-Administration Behavior in the Rhesus Monkey
}

\author{
M. C. Wilson* and C. R. Schuster** \\ Pharmacology Department, University of Michigan Medical School \\ Ann Arbor, Michigan
}

Received June 22, 1972

\begin{abstract}
The effects of acute intramuscular pretreatment with several dosages of a variety of centrally acting compounds on intravenous cocaine self-administration behavior were ascertained. Pretreatment with morphine and pentobarbital produced no change in this behavior until dosages $(2.0 \mathrm{mg} / \mathrm{kg}$ and $15.0 \mathrm{mg} / \mathrm{kg}$ respectively) were administered which grossly depressed grooming, exploratory, and locomotor activity behaviors. $d$-amphetamine $(0.5-4.0 \mathrm{mg} / \mathrm{kg})$ and phenmetrazine $(2.0-12.0 \mathrm{mg} / \mathrm{kg})$ pretreatment produced a dose-related decrease in cocaine self-administration. Trifluoperazine in dosages of $0.01-0.1 \mathrm{mg} / \mathrm{kg}$ increased the frequency of this behavior; whereas, higher dosages $(0.2,0.4 \mathrm{mg} / \mathrm{kg})$ grossly depressed behavior. Imipramine $(10-50 \mathrm{mg} / \mathrm{kg})$ produced a dose-related decrease in cocaine self-administration. Potential mechanisms of these drug-behavior and drug - drug interactions are discussed.
\end{abstract}

Key words: Self-Administration - Cocaine - Morphine - Pentobarbital Trifluoperazine.

Previous investigations have demonstrated an inverse relationship between reinforcing unit dosages (dosage per injection) and the frequency of psychomotor stimulant (including cocaine) intravenous selfadministration behavior in Rhesus monkeys (Wilson, Hitomi, and Schuster, 1971; Woods and Schuster, 1968; Goldberg, Hoffmeister, Schlichting, and Wuttke, 1971). Furthermore, when allowed limited daily access to these agents, a subject's total daily drug intake was very stable. Similar results have also been reported by several authors using rats as experimental subjects with intravenously self-administered cocaine (Pickens and Thomson, 1968), methamphetamine (Pickens, Meisch, and McGuire, 1967) and $d$-amphetamine (Pickens and Harris, 1968). The result of this inverse relationship is that subjects daily self-

* Presently located in the Department of Pharmacology, School of Pharmacy, University of Mississippi, University, Mississippi, 38677.

** Presently located in the Departments of Psychiatry and Pharmacology, University of Chicago, Chicago, Illinois, 60637. 
administer approximately the same amount of a psychomotor stimulant under limited access conditions. The mechanism underlying the stability of this behavior is obscure. Possible explanations would include (1) the drug in a dose dependent fashion may disrupt any ongoing behavior, (2) at higher dosages the drug may produce aversive effects e.g. stimulation, and these may predominate over any increased reinforcing efficacy or, (3) perhaps drug-related changes in neurotransmitter levels are occurring which in some manner make the self-administration of additional quantities of the psychomotor stimulants non-reinforcing.

Earlier studies have demonstrated that this stability of drug intake can be altered by prior treatment with other centrally active compounds.

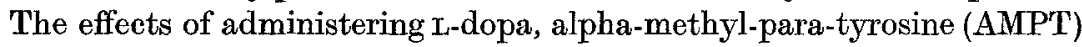
and methamphetamine on intravenous methamphetamine self-administration behavior in rats have been determined (Pickens, Meisch, and Dougherty, 1968). These investigators found that pretreatment with metamphetamine decreased the frequency of the behavior; whereas, AMPT increased self-administration behavior and L-dopa pretreatment had little effect.

The present authors have demonstrated that acute and chronic intramuscular treatment with chlorpromazine $(0.125-4.0 \mathrm{mg} / \mathrm{kg})$ immediately prior to a four-hour experimental session greatly increased the amount of the psychomotor stimulant (cocaine, phenmetrazine, methyl. phenidate, pipradrol and $d$-amphetamine) self-administered (Wilson and Schuster, 1972). Larger doses of chlorpromazine nonselectively suppressed orienting, locomotor activity, exploratory and grooming behaviors. We had suggested that the increase in self-administration behavior may have resulted from chlorpromazine partially blocking the reinforcing effect of the psychomotor stimulants. Previous studies had shown that decreases in unit dosage resulted in an increased frequency of self-administration behavior. Thus pretreatment with chlorpromazine may be analogous to reducing the effective unit dosage. Another interpretation of this chlorpromazine pretreatment data is that the increased frequency of self-administration of cocaine is an attempt on the part of the organism to re-establish a homeostatic level on a stimulation-depression continuum. Therefore, it is of importance to determine whether chlorpromazine is unique in this action or whether any drug producing central nervous system depression would produce comparable changes in the self-administration frequency of psychomotor stimulant drugs. If this hypothesis is correct, pretreatment with psychomotor stimulants should produce a decrease in stimulant self-administration behavior. In an effort to determine the validity of this stimulation-depression hypothesis of explaining the chlorpromazine results, the following studies were conducted. 


\section{Method}

The subjects for the study were eight adult male Rhesus monkeys weighing between 3.8 and $5.0 \mathrm{~kg}$. The subjects had free access to water and were fed twice daily. These animals were housed in individual open-faced experimental cubicles (Wilson et al., 1971) and were restrained in this environment by a stainless steel harness and restraining arm (Yanagita, Deneau, and Seevers, 1965).

Siliconized rubber catheters (I.D. $=0.033$ inches, 0. D. $=0.065$ inches) were implanted in the right internal jugular vein and the subjects were conditioned to lever-press for $0.2 \mathrm{mg} / \mathrm{kg}$ of cocaine hydrochloride on a continuous schedule of reinforcement (CRF). The cocaine solutions were prepared every third day by dissolving a gram of cocaine hydrochloride in a liter of sterile physiological saline $(1.0 \mathrm{mg} / \mathrm{ec})$. The injection volume was $0.2 \mathrm{ml} / \mathrm{kg}$ of body weight and each injection cycle lasted 45-60 sec depending on the subject's weight. During an injection cycle a stimulus light over the response lever was turned off and lever-presses emitted during this time had no consequence.

Once this self-administration behavior was conditioned, the drug access period, which was indicated by the illumination of the stimulus light, was reduced from $24 \mathrm{~h}$ to $4 \mathrm{~h}$ a day (11:00 a.m. $-3: 00$ p.m.). The duration of the drug access period was reduced to decrease the frequency of toxic drug effects and to provide a stable behavioral baseline. Daily drug intake for each subject stabilized ( $<10 \%$ change in total drug intake) within three days after the drug access period had been reduced to $4 \mathrm{~h}$. Experimental sessions were conducted daily, seven days a week.

The effects of acute pretreatment with imipramine hydrochloride, morphine sulfate, pentobarbital sodium, $d$-amphetamine sulfate, phenmetrazine hydrochloride, and trifluoperazine hydrochloride on this self-administration behavioral baseline were ascertained. At least four dosages of each of these compounds were tested twice in each of four subjects. The sequence of dosages was randomized amoung the four subjects. The testing of all dosages of a given drug was completed in a subject before testing with another compound was begun. At least two weeks elapsed between testing of different drugs in the same subject to negate the possibility of drug interactions. In addition, at least three days separated drug pretreatment sessions during the testing of each compound. Saline pretreatment sessions were conducted at various times during the course of the study to control for effects of the injection procedure.

All pretreatment drug solutions were prepared on the day on which they were to be administered. The compounds were dissolved in sterile physiological saline at various concentrations. The injection volume was kept constant at $0.5 \mathrm{ml}$. Drugs were administered intramuscularly $5 \mathrm{~min}$ before the start of the experimental session.

\section{Results}

Fig. 1 (upper graph) illustrates the mean percentage change in responding from cocaine baseline as a function of the pretreatment dosage of pentobarbital. Cocaine baseline is calculated as the mean of the last three days of cocaine self-administration prior to each test session. The points represent the mean values obtained from two tests in each of four subjects and the vertical lines indicate the range. The brackets at the left indicate the range for twenty saline pretreatment sessions, 


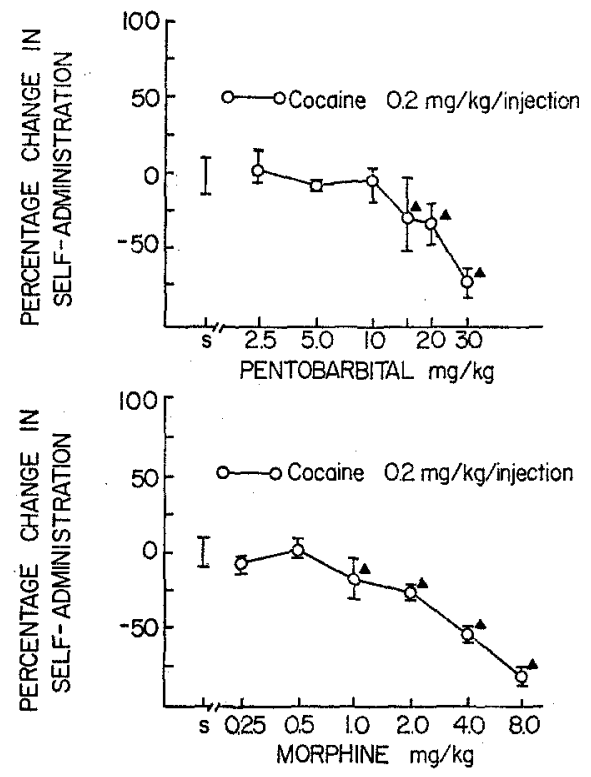

Fig. 1. Mean percentage change in cocaine self-administration as a function of the pretreatment dosage of pentobarbital (upper graph) and of morphine (lower graph). Each point represents the mean of four subjects and the vertical lines illustrate the range. The brackets at the left represent the range of change in cocaine self-administration which occurred following pretreatment with saline. Five of these control sessions were conducted in each subject. Those points denoted by a solid triangle are statistically different from saline $(p<0.05)$

five conducted in each subject. Pentobarbital pretreatment with dosages of $2.5,5.0$, and $10.0 \mathrm{mg} / \mathrm{kg}$ produced no change in self-administration behavior. Further increments in dosage produced a dose-related depres. sion of this behavior. This was accompanied by gross evidence of depression of grooming, exploratory and locomotor activity especially with the $30.0 \mathrm{mg} / \mathrm{kg}$ dosage. Table 1 indicates that the decrements in selfadministration behavior occurred primarily during the first and second hours of the session. With the $15 \mathrm{mg} / \mathrm{kg}$ dosage behavioral recovery occurred during the second hour; with the $20 \mathrm{mg} / \mathrm{kg}$ dosage, during the third hour; however with the $30 \mathrm{mg} / \mathrm{kg}$ pretreatment dosage, complete recovery of self-administration behavior to control rates did not occur during the remainder of the session. In general, evidence of gross behavioral depression paralleled the time course of the decrease in cocaine selfadministration behavior. Increases above control rates of responding during initial behavioral recovery did not occur in any subject with any pretreatment dosage of pentobarbital. 
Table 1. Intravenous cocaine self-administration during each hour of a daily session following intramuscular pretreatment with saline and with pentobarbital, morphine and trifluoperazine

\begin{tabular}{|c|c|c|c|c|c|}
\hline $\begin{array}{l}\text { Pretreatment } \\
\text { drug }\end{array}$ & $\mathrm{mg} / \mathrm{kg}$ & First hour & Second hour & Third hour & Fourth hour \\
\hline Saline & & $4.7(3.9-5.8)$ & $3.8(2.8-5.3)$ & $4.5(3.5-6.2)$ & $5.3(4.0-6.3)$ \\
\hline Pentobarbital & 2.5 & 3.5 & 4.2 & 5.1 & 4.9 \\
\hline Pentobarbital & 5.0 & 3.8 & 4.0 & 5.2 & 5.5 \\
\hline Pentobarbital & 10.0 & 3.0 & 4.3 & 5.0 & 5.2 \\
\hline Pentobarbital & 15.0 & 1.0 & 3.5 & 5.8 & 5.0 \\
\hline Pentobarbital & 20,0 & 0.8 & 0.7 & 4.0 & 4.3 \\
\hline Pentobarbital & 30.0 & 0.5 & 0.3 & 2.1 & 3.0 \\
\hline Saline & & $7.2(6.8-8.0)$ & $5.2(4.6-5.8)$ & $4.5(4.0-5.6)$ & $4.4(4.0-5.0)$ \\
\hline Morphine & 0.25 & 7.5 & 4.9 & 4.9 & 4.7 \\
\hline Morphine & 0.5 & 7.0 & 4.0 & 5.4 & 4.4 \\
\hline Morphine & 1.0 & 4.4 & 3.8 & 3.8 & 3.2 \\
\hline Morphine & 2.0 & 5.2 & 3.2 & 2.8 & 2.2 \\
\hline Morphine & 4.0 & 2.8 & 2.8 & 2.8 & 2.8 \\
\hline Morphine & 8.0 & 1.6 & 1.2 & 1.6 & 1.6 \\
\hline Saline & & $4.4(4.0--4.8)$ & $3.2(2.8-4.0)$ & $3.6(3.2-4.8)$ & $4.0(3.0-4.8)$ \\
\hline Trifluoperazine & 0.005 & 4.1 & 3.7 & 4.3 & 3.9 \\
\hline Trifluoperazine & 0.010 & 4.2 & 4.6 & 6.0 & 4.4 \\
\hline Trifluoperazine & 0.025 & 6.0 & 8.2 & 6.6 & 6.4 \\
\hline Trifluoperazine & 0.05 & 6.6 & 7.2 & 7.6 & 6.8 \\
\hline Trifluoperazine & 0.10 & 8.8 & 9.2 & 8.8 & 8.8 \\
\hline Trifluoperazine & 0.20 & 5.2 & 0.0 & 0.0 & 0.0 \\
\hline Trifluoperazine & 0.40 & 4.4 & 0.0 & 0.0 & 0.0 \\
\hline
\end{tabular}

The data illustrated for each drug was obtained from a single subject which was quite representative of the other three subjects tested with that compound. The figures represent the mean cocaine intake $(\mathrm{mg} / \mathrm{kg})$ for the two pretreatment sessions in which each treatment dosage was studied. The figures for saline represents the mean and range for five saline pretreatment session

The effects of morphine pretreatment on cocaine self-administration were qualitatively the same as with pentobarbital pretreatment. Fig.1 (lower graph) illustrates that intramuscular pretreatment with 0.25 and $0.5 \mathrm{mg} / \mathrm{kg}$ of morphine had no effect on this behavior. Further increases in pretreatment dosage to $1.0,2.0,4.0$, and $8.0 \mathrm{mg} / \mathrm{kg}$ produced a dose-related depression in cocaine self-administration. This behavioral decrement occurred only in the presence of depression of grooming, exploratory activity, locomotor activity and orienting behaviors and 


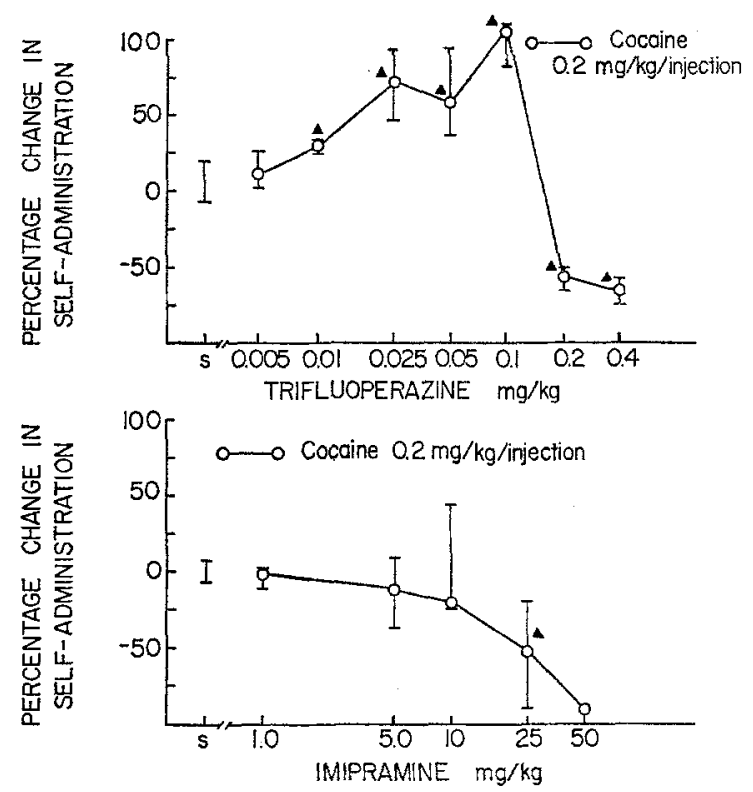

Fig.2. Mean percentage change in cocaine self-administration as a function of the pretreatment dosage of trifluoperazine (upper graph) and of imipramine (lower graph). Each point represents the mean of four subjects with the exception of the $50 \mathrm{mg} / \mathrm{kg}$ dose of imipramine. The vertical lines illustrate the range. The brackets at the left represent the range of change in cocaine self-administration which occurred following pretreatment with saline. Five of these control sessions were conducted in each subject. Those points denoted by a solid triangle are statistically different from saline $(p<0.05)$

therefore appeared to be a non-specific behavioral effect. Table 1 indicates that the $1.0,2.0,4.0$, and $8.0 \mathrm{mg} / \mathrm{kg}$ dosages of morphine produced decreases in self-administration behavior during all $4 \mathrm{~h}$ of the experimental session. In general this decrease was dose-related and the decrease in cocaine intake was rather constant for each of the $4 \mathrm{~h}$ for any given pretreatment dosage. Gross behavioral depression produced by these pretreatment dosages of morphine was also dose-related.

Trifluoperazine pretreatment, unlike morphine and pentobarbital, produced an increase in cocaine self-administration behavior. Fig. 2 (upper graph) illustrates that pretreatment dosages from 0.025 to $0.1 \mathrm{mg} / \mathrm{kg}$ increased cocaine self-administration from 50 to $100 \%$. There was no evidence of gross behavioral depression with these dosages. However, autonomic (e.g., pupillary dilatation and salivation) and motor effects of the cocaine were less prominent than under control conditions even though much more cocaine was self-administered. Pretreatment 
with $0.005 \mathrm{mg} / \mathrm{kg}$ produced no change in cocaine self-administration; however, pretreatment with $0.01 \mathrm{mg} / \mathrm{kg}$ did increase cocaine selfadministration somewhat in two of the four subjects. Pretreatment with 0.2 and $0.4 \mathrm{mg} / \mathrm{kg}$ of trifluoperazine greatly decreased cocaine selfadministration. All of the cocaine self-administered following pretreatment with these higher dosages occurred within the first $15 \mathrm{~min}$ of the experimental session before the onset of the phenothiazine's actions as illustrated in Table 1. These dosages produced depression of various normal behaviors such as locomotor activity, grooming and exploratory activity although the subjects could be aroused by auditory stimuli e.g., finger snapping. The subjects exhibited a prominent neuroleptic syndrome and plasticity, i.e., the investigator could place the subject in an abnormal position and the subject would remain in such a posture. On occasion these subjects would remain in such a position for an hour or longer. Some of the effects of these higher dosages were in evidence for over $24 \mathrm{~h}$. In two of the subjects, cocaine self-adminstration was above control levels on the day following pretreatment with the $0.4 \mathrm{mg} / \mathrm{kg}$ dose. Table 1 demonstrates that for that particular subject following pretreatment with $0.01 \mathrm{mg} / \mathrm{kg}$ of trifluoperazine, cocaine intake was increased during the second and third hours of the session but had returned to baseline levels during the last hour. The table further illustrates that pretreatment with $0.025,0.05,0.1 \mathrm{mg} / \mathrm{kg}$ increased cocaine intake during all $4 \mathrm{~h}$ of the session and that in general, the increase was dose-related. Pretreatment with $0.2 \mathrm{mg} / \mathrm{kg}$ produced a slight increase in cocaine intake during the first hour. However, all of this cocaine was self-administered during the first $15-20 \mathrm{~min}$. Cocaine intake was completely abolished during the remaining $3 \mathrm{~h}$ of the session. Similarly, pretreatment with $0.4 \mathrm{mg} / \mathrm{kg}$ of trifluoperazine abolished cocaine self-administration during the latter $3 \mathbf{h}$ of the session. During the first hour, cocaine intake was normal; however, all of it was selfadministered within the first min of the session rather than intermittently throughout the hour as during control sessions.

Fig. 3 demonstrates that pretreatment with other psychomotor stimulants produced a dose-related decrease in cocaine self-administration behavior. Pretreatment with $0.5 \mathrm{mg} / \mathrm{kg}$ of $d$-amphetamine decreased cocaine self-administration by about $11 \%$; whereas, $4.0 \mathrm{mg} / \mathrm{kg}$ almost completely suppressed cocaine self-administration. Intermediate pretreatment dosages of 1.0 and $2.0 \mathrm{mg} / \mathrm{kg}$ decreased cocaine self-administration by $25 \%$ and $50 \%$ respectively. The gross behavioral effects and visable autonomic actions exhibited by the subjects appeared by direct visual observation to be qualitatively and quantitatively the same during all pretreatment and control sessions. Table 2 demonstrates that pretreatment with $0.5 \mathrm{mg} / \mathrm{kg}$ tended to reduce cocaine intake during 


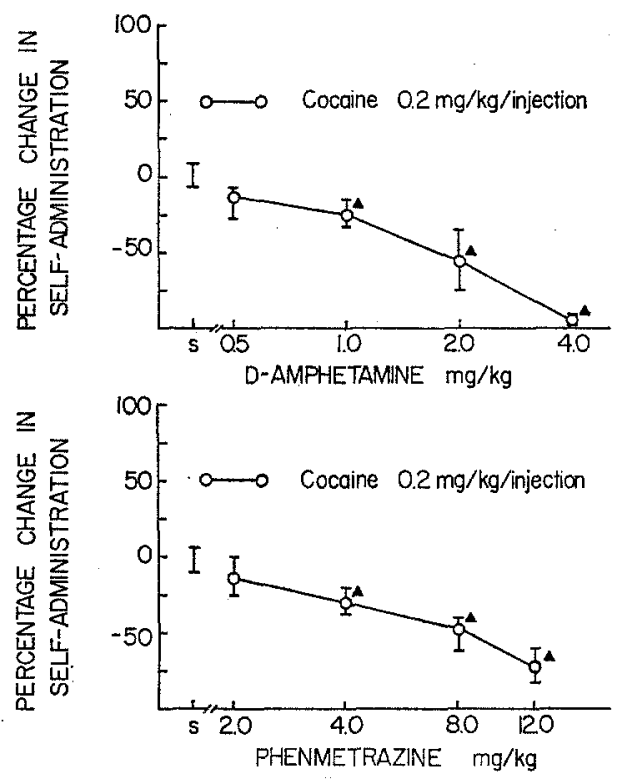

Fig. 3. Mean percentage change in cocaine self-administration as a function of the pretreatment dosage of $d$-amphetamine (upper graph) and of phenmetrazine (lower graph). Each point represents the mean of four subjects and the vertical lines illustrate the range. The brackets at the left represent the range of change in cocaine self-administration which occurred following pretreatment with saline. Five of these control sessions were conducted in each subject. Those points denoted by a solid triangle are statistically different from saline $(p<0.05)$

the first $3 \mathrm{~h}$, but this behavior returned to baseline levels during the last hour. Pretreatment with $1.0 \mathrm{mg} / \mathrm{kg}$ decreased cocaine intake during all $4 \mathrm{~h}$ of the session with the decrease being least prominent in the last hour. Likewise, pretreatment with 2.0 and $4.0 \mathrm{mg} / \mathrm{kg}$ of $d$-amphetamine decreased cocaine intake during all $4 \mathrm{~h}$ of the session. Self-administration behavior was completely suppressed during the second and third hours and during the second, third, and fourth hours respectively. Following pretreatment with these two dosages, all cocaine intake in the first hour occurred within the first $10-15 \mathrm{~min}$.

Fig. 3 illustrates that-phenmetrazine pretreatment had qualitatively the same effects on cocaine self-administration as pretreatment with $d$-ampetamine. On a $\mathrm{mg} / \mathrm{kg}$ basis, phenmetrazine appeared to be about one-fourth as potent in reducing cocaine self-administration. In two of the four subjects, pretreatment with $2.0 \mathrm{mg} / \mathrm{kg}$ phenmetrazine decreased cocaine self-administration approximately $20 \%$; whereas, no observable effect occurred in the other two subjects. Increases in pre- 
Table 2. Intravenous cocaine self-administration during each hour of a daily session following intramuscular pretreatment with saline and with imipramine, $d$-amphetamine, and phenmetrazine

\begin{tabular}{|c|c|c|c|c|c|}
\hline $\begin{array}{l}\text { Pretreatment } \\
\text { drug }\end{array}$ & $\mathrm{mg} / \mathrm{kg}$ & First hour & Second hour & Third hour & Fourth hour \\
\hline Saline & & $7.4(5.4-7.8)$ & $5.8(5.4-6.4)$ & $5.6(4.6-6.8)$ & $4.8(4.4-5.4)$ \\
\hline $\begin{array}{l}\text { Imipramine } \\
\text { Imipramine } \\
\text { Imipramine } \\
\text { Imipramine } \\
\text { Imipramine }\end{array}$ & $\begin{array}{r}1.0 \\
5.0 \\
10.0 \\
25.0 \\
50.0\end{array}$ & $\begin{array}{l}7.6 \\
6.4 \\
5.4 \\
1.0 \\
1.0\end{array}$ & $\begin{array}{l}5.8 \\
6.2 \\
4.4 \\
0.4 \\
0.0\end{array}$ & $\begin{array}{l}6.0 \\
4.4 \\
3.6 \\
0.6 \\
0.0\end{array}$ & $\begin{array}{l}4.5 \\
4.2 \\
4.0 \\
1.4 \\
0.0\end{array}$ \\
\hline Saline & & $6.2(4.9-7.2)$ & $4.6(4.2-5.1)$ & $4.8(4.4-5.1)$ & $4.4(4.0-4.8)$ \\
\hline $\begin{array}{l}d \text {-amphetamine } \\
d \text {-amphetamine } \\
d \text {-amphetamine } \\
d \text {-amphetamine }\end{array}$ & $\begin{array}{l}0.5 \\
1.0 \\
2.0 \\
4.0\end{array}$ & $\begin{array}{l}4.4 \\
4.0 \\
2.2 \\
1.0\end{array}$ & $\begin{array}{l}3.0 \\
3.0 \\
0.0 \\
0.0\end{array}$ & $\begin{array}{l}4.0 \\
2.4 \\
0.0 \\
0.0\end{array}$ & $\begin{array}{l}4.0 \\
3.8 \\
2.8 \\
0.0\end{array}$ \\
\hline Saline & & $5.3(4.8-5.7)$ & $4.2(3.7-4.5)$ & $4.7(4.2-5.2)$ & $5.0(4.4-5.5)$ \\
\hline $\begin{array}{l}\text { Phenmetrazine } \\
\text { Phenmetrazine } \\
\text { Phenmetrazine } \\
\text { Phenmetrazine }\end{array}$ & $\begin{array}{r}2.0 \\
4.0 \\
8.0 \\
12.0\end{array}$ & $\begin{array}{l}4.1 \\
2.5 \\
1.0 \\
0.8\end{array}$ & $\begin{array}{l}3.7 \\
3.5 \\
0.5 \\
0.0\end{array}$ & $\begin{array}{l}5.1 \\
4.3 \\
2.4 \\
2.8\end{array}$ & $\begin{array}{l}5.5 \\
4.7 \\
3.2 \\
3.6\end{array}$ \\
\hline
\end{tabular}

The data illustrated for each drug was obtained from a single subject which was quite representative of the three subjects tested with that compound. The figures represent the mean cocaine intake $(\mathrm{mg} / \mathrm{kg}$ ) for the two pretreatment sessions in which each treatment dosage was studied. The figures for saline represents the mean and range for five saline pretreatment sessions.

treatment dosage to $4.0,8.0$ and $12.0 \mathrm{mg} / \mathrm{kg}$ produced a dose-related decrease in cocaine intake in all subjects. The gross behavior and appearance during drug pretreatment sessions appeared to be the same as during saline control sessions even though much less cocaine was self-administered.

Table 2 demonstrates that the decrease in cocaine intake produced by pretreatment with $4.0 \mathrm{mg} / \mathrm{kg}$ of phenmetrazine occurred primarily during the first $2 \mathrm{~h}$ of the session. Pretreatment with 8.0 and $12.0 \mathrm{mg} / \mathrm{kg}$ decreased cocaine self-administration during all $4 \mathrm{~h}$ but primarily in the first and second hours. In general the duration of the decrease in cocaine self-administration produced by phenmetrazine was shorter than that produced by $d$-amphetamine.

Pretreatment with imipramine also decreased cocaine self-administration as illustrated in Fig.2 (lower graph). Pretreatment with $1.0 \mathrm{mg} / \mathrm{kg}$ produced no observable change in cocaine self-administration in three of 
the four subjects. Table 2 demonstrates that the pattern of responding for cocaine was very similar to saline pretreatment sessions with this dosage. Pretreatment with $5.0 \mathrm{mg} / \mathrm{kg}$ produced a decrease in this behavior in two of the four subjects and this effect occurred during the latter $2 \mathrm{~h}$ of the session as illustrated in Table 2. Pretreatment with this dosage produced no observable change in cocaine self-administration in the remaining two subjects. Cocaine self-administration was decreased in three of the four subjects following pretreatment with $10.0 \mathrm{mg} / \mathrm{kg}$; however, in the other subject, this dosage increased this behavior. When this dosage was repeated in this subject, a slight decrease in cocaine self-administration occurred. In those three subjects in which a decrease initially occurred in cocaine self-administration, cocaine intake was reduced during the last $3 \mathrm{~h}$ of the session. Further increases in pretreatment dosage to 25.0 and $50.0 \mathrm{mg} / \mathrm{kg}$ produced a dose-related decrease in cocaine self-administration. The decrease, produced by the $25 \mathrm{mg} / \mathrm{kg}$ dosage, was observed during all $4 \mathrm{~h}$ of the session in each of the subjects. The grossly observable behavioral and autonomic appearance of three of the four subjects was qualitatively similar to that seen during saline control pretreatment sessions. However, in one of the four subjects, clonic convulsions occurred during the second hour of the session. Similarly, convulsions occurred during the first hour in the first subject pretreated with $50.0 \mathrm{mg} / \mathrm{kg}$ of imipramine. This was a different subject than the one which had convulsed with the $25.0 \mathrm{mg} / \mathrm{kg}$ dose. Since it was evident that this drug dosage combination may produce potentially lethal results, this subject was the only animal pretreated with this dosage. Table 2 illustrates that this subject selfadministered only five injections for a total of $1.0 \mathrm{mg} / \mathrm{kg}$ of cocaine prior to the convulsions, but he did not re-engage in self-administration behavior during the session.

\section{Diseussion}

The effects of morphine and pentobarbital pretreatment on cocaine self-administration behavior indicate that drug-induced CNS depression does not alter the reinforcing properties of cocaine. If the converse were true then some dose of morphine and/or pentobarbital that produces a small amount of depression, which could easily be overcome by cocaine-induced stimulation, should have produced an increase in cocaine self-administration. If one assumes that it is the central stimulating properties of cocaine and similar compounds which provides them with reinforcing efficacy, then simplistically it could be argued that any compound which antagonizes the stimulant action would decrease the reinforcing efficacy of cocaine. Previous studies on cocaine selfadministration (Wilson et al., 1971; Pickens and Thomson, 1968; 1971) 
have demonstrated that a decrease in the dosage per injection of cocaine results in an increase in self-administration behavior. Therefore, drug-induced antagonism of the reinforcing property should also result in an increase in the frequency of this behavior. Cocaine selfadministration did not increase in any of the subjects pretreated with any of the doses of pentobarbital or morphine studied. It was apparent that the higher dosages $(15.0,20.0$ and $30.0 \mathrm{mg} / \mathrm{kg}$ of pentobarbital and $8.0 \mathrm{mg} / \mathrm{kg}$ of morphine) did produce generalized non-specific central depression. Locomotor activity, grooming behavior, and exploratory behavior although not objectively measured were depressed with these dosages. It is assumed that cocaine self-administration was reduced with these dosages due to the non-selective incapacitating action of these drugs. Previous investigators (Clark and Samuel, 1969) have demonstrated that the administration of pentobarbital $10.0 \mathrm{mg} / \mathrm{kg}$ had no effect on conditioned avoidance response performance. However, a dose of $15.0 \mathrm{mg} / \mathrm{kg}$ produced a nonselective disruption of both escape and avoidance behavior. A decrease in cocaine self-administration produced by pretreatment with pentobarbital first occurred with the $15.0 \mathrm{mg} / \mathrm{kg}$ dose. It is possible that only with these higher dosages was there an antagonism of the reinforcing property of cocaine and that the subject was physically incapable of performing the appropriate compensatory response due to ataxia, etc. Lower pretreatment dosages possibly did not antagonize the reinforcing action of cocaine and therefore the subject's response rate did not change even though it was within the subject's physical capability to do so. The effects of morphine and pentobarbital pretreatment on this behavior differ qualitatively from those produced by chlorpromazine (CPZ) pretreatment (Wilson and Schuster, 1972). This agent in dosages of $0.125-4.0 \mathrm{mg} / \mathrm{kg}$ increased. intravenous cocaine self-administration in monkeys. Further increments in CPZ dosage produced marked non-specific behavioral depression. Apparently, it was not the central depressant action of chlorpromazine but rather a more selective action of CPZ which resulted in an increase in cocaine self-administration behavior.

The results of trifluoperazine pretreatment are very similar to those obtained previously with chlorpromazine, as would be expected, and trifluoperazine was more potent on a $\mathrm{mg}$ basis in this action than chlorpromazine. The peak percentage increase seen with trifluoperazine pretreatment was double that seen with chlorpromazine pretreatment indicating that trifluoperazine may have a more selective action on increasing cocaine self-administration behavior than chlorpromazine. The exact mechanism of the rate-increasing effect which the phenothiazines have on cocaine self-administration remains obscure. Perhaps the phenothiazines antagonize the reinforcing property of cocaine, which as 
mentioned previously, results in increased self-administration behavior. An alternative hypothesis is that phenothiazines may antagonize aversive properties of cocaine which limit their self-administration (Wilson and Schuster, 1972). Furthermore, perhaps chlorpromazine and trifluoperazine antagonize a general behavior-disrupting toxic action of cocaine which then may result in an increase in self-administration behavior. It has been demonstrated that cocaine disrupts ongoing foodreinforced behavior (Pickens and Thompson, 1968). Whether this effect is specific for food-reinforced behavior, i.e. anorexia, is uncertain. Such a behavior-disrupting action would lead to stable cocaine intake, i.e., the postreinforcement pause following each cocaine injection would be proportional to dosage per injection. Another possible mechanism for this cocaine-phenothiazine interaction is that the phenothiazines may alter the pharmacodynamics, i.e. absorption, metabolism, etc. of cocaine and in this manner shorten the reinforcing, aversive, or behavior-disrupting properties of each injection of cocaine. Once the mechanism responsible for stability of psychomotor stimulant administration is delineated, then the mechanism of this particular interaction can more definitively be studied.

The dose-related decrease in cocaine self-administration produced by treatment with $d$-amphetamine and phenmetrazine also could be interpreted in many ways. In general, the behavioral pharmacology of these three agents is qualitatively similar. Each of these agents has been extensively abused and apparently the reinforcement i.e. "high" or euphoria produced clinically by these agents is qualitatively similar in nature (Kramer, Fischman, and Littlefield, 1967). It has previously been demonstrated that the effect of chlorpromazine pretreatment on self-administration of each of these agents in monkeys is also qualitatively similar (Wilson and Schuster, 1972) Also the intravenous self-administration pattern of each of these psychomotor stimulants is very stable (Wilson et al., 1971). Therefore, it would appear that chlorpromazine is increasing the self-administration of each via a common mechanism which in turn leads to speculation that a common action of all three is responsible for the stability of self-administration behavior. Pretreatment with phenmetrazine or $d$-amphetamine may then simply substitute for the cocaine i.e., these agents may also share a common mechanism for limiting their self-administration as well as sharing a similar reinforcement mechanism. Both of these agents have a longer duration of action than cocaine, especially d-amphetamine. Therefore, it is not surprising that a single pretreatment injection of the total dosage of either drug normally self-administered during a $4 \mathrm{~h}$ session (Wilson et al., 1971) almost completely suppressed cocaine self-administration. Other investigators had previously demonstrated that pretreatment 
with the psychomotor stimulant being self-administered resulted in a dose-related depression of self-administration behavior (Pickens et al., 1968).

Pretreatment with imipramine also may have substituted for (or potentiated) some of the actions of cocaine. Both imipramine and cocaine have been shown to block the uptake of norepinephrine peripherally (Whitby, Hertting, and Axelrod, 1960; Carlsson, Fuxe, Hamberger, and Lindgvist, 1966) and furthermore it has been demonstrated that imipramine blocks the uptake of norepinephrine in vivo centrally (Glowinski and Axelrod, 1964). However, it has also been demonstrated that cocaine in vivo fails to centrally block norepinephrine uptake (Glowinski and Axelrod, 1965). In vitro studies have indicated that cocaine can interfer with the uptake of norepinephrine in brain slices (Hamberger and Masuoka, 1965). It has been demonstrated that imipramine decreases norepinephrine re-uptake within $4 \mathrm{~h}$ following its acute administration in rats. It has also been reported by Angel and Roberts (1966) that treatment with imipramine increases cerebrovascular permeability to cocaine in the rat. This would in effect increase the unit dosage of cocaine which several investigators have shown results in a decrease in the frequency of self-administration behavior. If the postreinforcement pause in cocaine self-administration behavior is due to an action mediated by norepinephrine, then it would be suspected that imipramine may reduce the frequency of cocaine self-administration behavior. As previously mentioned, imipramine-treated animals who self-administered much less cocaine appeared identical (e.g. behavior, autonomic activity) to saline control subjects which self-administered much more cocaine. Pretreatment with $25 \mathrm{mg} / \mathrm{kg}$ of imipramine resulted in convulsions in one subject and also the only animal treated with $50.0 \mathrm{mg} / \mathrm{kg}$ of imipramine convulsed.

The results obtained from this study indicate the need for the conduction of further studies to ascertain if there are other drugs which can alter the reinforcing property of the psychomotor stimulants. Such compounds might be useful in the treatment of humans who are psychologically dependent on psychomotor stimulant drugs.

This study was supported by NIMH Grant No. MHH-12084 and by NIMH Grant No. MH-18245.

\section{References}

Angel, C., Roberts, A.: Effect of electroshock and antidepressant drugs on cerebrovascular permeability to cocaine in the rat. J. nerv. ment. Dis. 142, 376-380 (1966).

Carlsson, A., Fuxe, K., Hamberger, B., Lindgvist, M.: Biochemical and histochemical studies on the effects of imipramine-like drugs and $(+)$-amphetamine 
on central and peripheral catecholamine containing neurons. Acta physiol. scand. 67, 481-497 (1966).

Clark, R., Samuel, C.: Drug effects on a discrete conditioned avoidance response in dogs, Rhesus monkeys, and rats. Psychopharmacologia (Berl.) 4, 106-114 (1969).

Glowinski, J.: Effects of drugs on the uptake, release and metabolism of $\mathrm{H}^{3}$-norpinephrine in the rat brain. J. Pharmacol. exp. Ther. 149, 43-49 (1965).

Glowinski, J., Axelrod, J.: Inhibition of uptake of tritiated-noradrenaline in the intact rat brain by imipramine and structurally related compounds. Nature (Lond.) 204, 1318-1319 (1964).

Goldberg, S. R., Hoffmeister, F., Schlichting, U., Wuttke, W.: A comparison of pentobarbital and cocaine self-administration in Rhesus monkeys: effects of dose and fixed-ratio parameters. J. Pharmacol. exp. Ther. 179, 277-283 (1971).

Hamberger, B., Masouka, D.: Localization of catecholamine uptake in rat brain slices. Acta pharmacol. (Kbh.) 22, 363-367 (1965).

Kramer, J., Fischman, V., Littlefield, D.: Amphetamine abuse: Patterns and effects of high doses taken intravenously. J. Amer. med. Ass. 201, 305-309 (1967).

Pickens, R., Harris, W.: Self-administration of D-amphetamine by rats. Psychopharmacologia (Berl.) 12, 158-163 (1968).

Pickens, R., Meisch, R., McGuire, L.: Methamphetamine reinforcement in rats. Psychonom. Sci. 8, 371-372 (1967).

Pickens, R., Meisch. R., Dougherty,J.: Chemical interactions in methamphetamine reinforcement. Psychol. Rep. 23, 1267-1270 (1968).

Pickens, R., Thompson, T.: Cocaine-reinforced behavior in rats: Effects of reinforcement magnitude and fixed-ratio size. J. Pharmacol. exp. Ther. 161, 122-129 (1968).

Whitby, L., Hertting, G., Axelrod, J.: Effect of cocaine on disposition of noradrenaline labelled with tritium. Nature (Lond.) 187, 604-605 (1960).

Wilson, M. C., Hitomi, M., Schuster, C. R.: Psychomotor stimulant self-administration as a function of dosage per injection in the Rhesus monkey. Psychopharmacologia (Berl.) 22, 271-281 (1971).

Wilson, M. C., Schuster, C. R.: The effeets of chlorpromazine on psychomotor stimulant self-administration in the Rhesus monkey. Psychopharmacologia (Berl.) 26, 115-126 (1972).

Woods, J., Schuster, C. R.: Reinforcement properties of morphine, cocaine and SPA as a function of unit dose. Int. J. Addict. 3, 231-237 (1968).

Yanagita, T., Deneau, G., Seevers, M.: Evaluation of pharmacological agents in the monkey by long-term intravenous self or programmed administration. Excerpta Medica International Congress Series 87, 453-457 (1965).

M. C. Wilson

University of Mississippi

School of Pharmacy

Department of Pharmacology

Mississippi 38677, U.S.A. 